RESEARCH ARTICLE

\title{
Health Literacy Level of Diabetic or Hypertensive Patients in Family Health Units in Portugal

\author{
Isabel Araújo ${ }^{\text {(D) }}$, Clara Simões ${ }^{2}$ (D), Nuno Araújo ${ }^{3}$ (D), Rui Jesus ${ }^{4}$ (D) Fernanda Pombal ${ }^{5}$ (D), \\ Filipe Fernandes $^{5}$ (D) and Bárbara Machado ${ }^{6 *}$ (D)
}

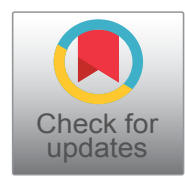

${ }^{1}$ Director of the Nursing Department at the Vale do Ave School of Health, North Polytechnic Institute of Health - Vila Nova de Famalicão; Researcher at CESPU, Institute for Research and Advanced Training in Health Sciences and Technologies, Portugal

${ }^{2}$ Principal Adjunct Professor at the Vale do Ave School of Health, North Polytechnic Institute of Health; Researcher at CESPU, Institute for Research and Advanced Training in Health Sciences and Technologies, Portugal

${ }^{3}$ Principal Adjunct Professor at the Vale do Ave School of Health, North Polytechnic Institute of Health, Portugal

${ }^{4}$ PhD in Educational Sciences, Principal Adjunct Professor at the Escola Superior de Saúde de Vale do Sousa; Instituto Politécnico de Saúde do Norte, Researcher at CESPU, Institute for Research and Advanced Training in Health Sciences and Technologies, Portugal

${ }^{5}$ Principal adjunct professor, Vale do Ave School of Health - IPSN-Cespu, Portugal

${ }^{6}$ PhD Student in Public Health, National School of Public Health, University of Lisbon, Portugal

*Corresponding author: Bárbara Pinheiro Machado, PhD Student in Public Health, National School of Public Health, University of Lisbon, Rua José António Vidal, 81, 4760-409 Vila Nova de Famalicão, Portugal
Abstract
Background: Health Literacy $(\mathrm{HL})$ is a multidimensional concept which core domains are: Health promotion, health care and disease prevention.
Objectives: To describe the HL level of a group of diabetics and/or hypertensive patients from a northern region of Por- tugal; To verify the influence of sociodemographic variables and clinical variables on the HL level.
Methods: Descriptive-exploratory cross-sectional quantita- tive study. Sample of convenience $n=664$ users enrolled in 3 groupings of health centers in the northern region of Portugal. A survey was used with the HL European Health Literacy Survey (HLS-EU-PT, translation valid for Portugal). Descriptive and inferential statistics techniques were used using IBM SPSS Statistics, software version 25. Ethical re- search principles were respected.
Results: An inadequate or problematic level of $\mathrm{HL}$ was noted with adult/elderly users. From the dimensions studied, it was found that it is easier for users to take care of their health and more difficult to promote health. Sociodemographic and clin- ical variables influence $\mathrm{HL}$ levels. Seeing the doctor and the nurse are fundamental educators to increase the level of $\mathrm{HL}$.

\begin{abstract}
Conclusion: More information and more time in the medical and nursing consultations can ease the users' management of the therapeutical regime, improve the decision making for health promotion and disease prevention.
\end{abstract}

What is already known about the Topic?

- International data refer to a general level of problematic or inadequate $\mathrm{HL}$, which includes Portugal. The most prevalent chronic non-communicable diseases are Diabetes and Hypertension.

- Portugal has the highest prevalence rate of diabetes in Europe and there are 3 million people with high blood pressure.

- The European Union stresses the promotion of health, disease prevention and the promotion of supportive environments for healthy lifestyles as a priority for the population. It is known that the HL level is an important variable in the health/disease process.

What this paper adds

-The evidence found partially responds to the National Program for Health, Literacy and Self-Care, referring to a micro context of the northern region of Portugal.

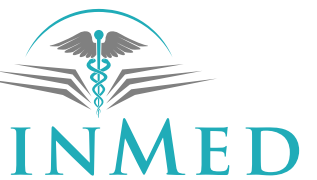

INTERNATIONAL LIBRARY

Citation: Araújo I, Simões C, Araújo N, Jesus R, Pombal F, et al. (2020) Health Literacy Level of Diabetic or Hypertensive Patients in Family Health Units in Portugal. Int Arch Nurs Health Care 6:145. doi. org/10.23937/2469-5823/1510145

Accepted: September 28, 2020: Published: September 30, 2020

Copyright: (C) 2020 Araújo I, et al. This is an open-access article distributed under the terms of the Creative Commons Attribution License, which permits unrestricted use, distribution, and reproduction in any medium, provided the original author and source are credited. 
- There was an inadequate or problematic level of $\mathrm{HL}$ in patients with Diabetes and/or Hypertension. Users are more likely to take care of health and less likely to promote it.

- In users' opinion, doctors and nurses are fundamental educators to enable them to provide more and better information for the effective management of their health project.

- The results show a multidisciplinary investment in the three dimensions of $\mathrm{HL}$, in order to effectively manage resources and increase health gains.

\section{Keywords}

Health literacy, Diabetes mellitus, Hypertension, Primary health care, Portugal

\section{Introduction}

Health Promotion (HP) contributes to the reduction of population diseases, especially when promoting healthy lifestyles. One of the HP strategies is health education. It aims at improving health, disease prevention, rehabilitation, transition or adaptation to a new condition of life. Health education empowers people to care for their health project, that is, to enable them to acquire the knowledge, skills and competencies to improve their quality of life and thus be responsible for their health and those around them [1].

Currently, chronic diseases are estimated as a growing public health problem because of the high mortality rates and disability they cause. According to the National Institute of Statistics (NIS), in Portugal it is estimated that $40.3 \%$ of the resident population, aged over 16 years, suffer from health problems or chronic diseases [2].

Chronic diseases, such as hypertension and Diabetes Mellitus (DM), are of increasing concern to health entities, both for their level of chronicity and for the wide range of effects they can have on people's daily lives [3].

Globally, it is estimated that more than 400 million adults have DM, with an expected growth estimate of more than 640 million adults by 2040 [4]. According to the World Health Organization (WHO), one in five adults worldwide has hypertension [5].

The Organization for Economic Co-operation and Development (OECD) says in its 2017 health report, Portugal is one of the countries with the highest prevalence of diabetes in Europe [4]. In parallel, in Portugal, there are 3 million people with AHT, that is, one in three [6].

Thus, chronic noncommunicable diseases such as hypertension and DM require the education and empowerment for people to achieve adequate control of the disease, to prevent complications and to take responsibility for the control of their health project and the groups where they are inserted [7].

To validate the above mentioned, the European Commission on Health Strategies points out as the fundamental principle in empowering citizens, the capaci- ty they have for decision-making in their health project [8]. As demonstrated by the literature on the subject, the empowerment of each person to act to effectively manage health resources is directly related to the level of Health Literacy (HL).

$\mathrm{HL}$ is a multidimensional concept which core domains include: i) Health care; (ii) Disease prevention and (iii) Health promotion. The first domain, health care, is defined as the ability to process information about health problems, to understand medical information, to interpret it and to evaluate it in order to make decisions about it. The domain of disease prevention is understood as the ability to process information about health risk factors, in order to understand them, interpret them and evaluate information to make decisions that protect health. Finally, health promotion is related to the ability to identify health determinants in social and physical environments, to understand the influence of contextual variables on individual or family health, and how to act on them to reduce their harmful effects. The $\mathrm{HL}$ also integrates four levels of information processing with regard to decision making: access, comprehension, evaluation and utilization [9-11].

$\mathrm{HL}$ has been the object of study because of the preponderant role it plays in maintaining a person's health and quality of life, as well as in their ability to actively manage their health condition, allowing for greater interaction with health professionals $[10,12,13]$. Thus, $\mathrm{HL}$ has an impact on the management of individual and community resources, translating into health gains [1315].

The level of $\mathrm{HL}$ is not a characteristic, but rather a state that partly reflects the experience of each person in their health/illness process [16]. The studies indicate that a person with a sufficient/excellent $\mathrm{HL}$ level is more likely to make clinical decisions in relation to the health of his/her family and the community where he/ she is inserted. Research results show that people with higher levels of $\mathrm{HL}$ reduce health care costs, are more knowledgeable about health, use health services less frequently, and when hospitalizations occur, they are of shorter duration [10].

In contrast, low HL levels are associated with greater difficulty in managing their own heath, in understanding and following instructions from health professionals, and in perceiving information leaflets. As service users, people with low $\mathrm{HL}$ levels tend to seek health care less frequently for health promotion and disease prevention, and when hospitalizations occur, they are longer and usually have complications resulting from poor chronic conditions [3].

Thus, HL has gained increasing importance in the area of health education, especially in empowering people to manage their health and the resources they have access to $[8,17-19]$, once it can contribute to the way people 
assimilate health knowledge and control the symptoms associated with their pathologies and contextual variables of the environment in which they live [20].

The scientific community has been awake to the monitoring of $\mathrm{HL}$ levels in different populations and contexts, in which a general level of problematic or inadequate $\mathrm{HL}$ stands out $[11,21,22]$.

Because of the implications of different HL levels, there is a growing concern about this in the formulation of European health policies. This is supported by the European Union's strategic health plan, which aims to promote health, disease prevention and promotion of supportive environments for healthy lifestyles. According to the Despacho n. $^{\circ} 3618-\mathrm{A} / 2016$ [23], it should be noted that in this strategy the operational objectives are to identify, disseminate and promote good evidence-based practice and good disease-prevention practice, as well as health promotion activities. In Portugal the Directorate-General for Health [12], proposed actions to promote $\mathrm{HL}$ as a measure of health promotion and disease prevention, particularly in chronic diseases and their associated risk factors.

Despite the importance of $\mathrm{HL}$, information about its level in populations remains low. As such, in 2016, the low HL levels observed in Portugal led the Government to prioritize health promotion through a new ambition for public health, particularly through the creation of the National Program for Health Literacy and Self-Care $[12,13]$.

Given the importance of the topic and the implications that the level of $\mathrm{HL}$ has for the effective management of the disease and, in particular, the chronic disease, we ask: What is the level of HL in people with diabetes mellitus and/or hypertension under treatment in Family Health Units from a region of Northern Portugal? This question was the subject of an investigation, the objectives of which were to describe the level of $\mathrm{HL}$ of a group of diabetics and/or hypertensives under treatment in a Family Health Unit of a Northern region of Portugal and to verify the influence of sociodemographic variables and clinical variables at the $\mathrm{HL}$ level of a group of diabetics and/or hypertensives.

\section{Materials and Methods}

A cross-sectional descriptive study was carried out. Data collection was conducted from February 2019 to May 2019 (authorization $n^{\circ} 99 / 2018$ ). A convenience sample $(n=664)$ was chosen as the result of data collection in three Health Center Groupings (ACES) of a region in the North of Portugal, with a total of 13842 subscribers. Inclusion criteria were defined as being diabetic, hypertensive or both, age equal to or older than 18 years, being enrolled in a Family Health Unit and attending the nursing consultation for diabetes or hypertension.

The data collection instrument was a questionnaire survey, divided into three groups, group I being composed of sociodemographic issues (gender, age, literacy, marital status and professional activity). Group II included the scale of the $\mathrm{HL}$ - European Health Literacy Survey $[10,24]$, validated for the Portuguese reality [15]. The scale is composed of 47 items, which integrate the three dimensions: Health care, disease prevention and health promotion - dimensions assessed in questions 1-16, 17-31 and 32-47, respectively, [24]. The answers to each of the 47 items obey a Likert scale (1. very difficult, 2. difficult, 3. easy, 4. very easy, 5 . do not know/no answer). The pre-assigned values for the scale assume a minimum value of zero and a maximum of 50 , with increasing values of literacy. Levels of literacy can still be divided into categories, classified as inadequate, problematic, sufficient and excellent [25]. The formula for calculating the various $\mathrm{HL}$ levels was as follows:

$$
\text { Score }=(\text { average }-1) \times(50 / 3) \text {. }
$$

Group III referred to the clinical variables (pathology, health services that have been used in the last 6 months and which health professional contributes to increase health knowledge), including an open question to request strategies to increase health literacy.

To collect the information, authorization was requested from the Ethics Committee of the Regional Health Administration of the North. Subsequently, a meeting was held with the coordinators of three groups of health centers (ACES), to present the project and request collaboration. At the time of the consultations, the users were invited to participate in the study, and a space with privacy for the collection of data was made available in each Family Health Unit (FHU). Ethical principles applied to human studies (the Helsinki Declaration) were respected and the informed consent form was applied. The anonymity and confidentiality of the data collected has been guaranteed and scrupulously respected.

In the overall characterization of the sample, the numerical variables were summarized through the mean and standard deviation (SD), and are presented in the text through the mean \pm SD. Qualitative variables were used for absolute and relative frequencies. Mann-Whitney tests ( $\mathrm{HL}$ comparison between two groups of subjects), ANOVA (comparison of HL between three or more groups of subjects) were used to verify the existence of relations between sociodemographic/clinical variables and HL. Pearson's correlation (relationship between age and $\mathrm{HL}$ ). All test values of the tests ( $p$-value) were considered statistically significant if they were less than 0.05 . Statistical analysis was performed using IBM SPSS software version 25 .

\section{Results}

In the first place the results of the descriptive analysis are presented, and then the results obtained through the inferential analysis. 


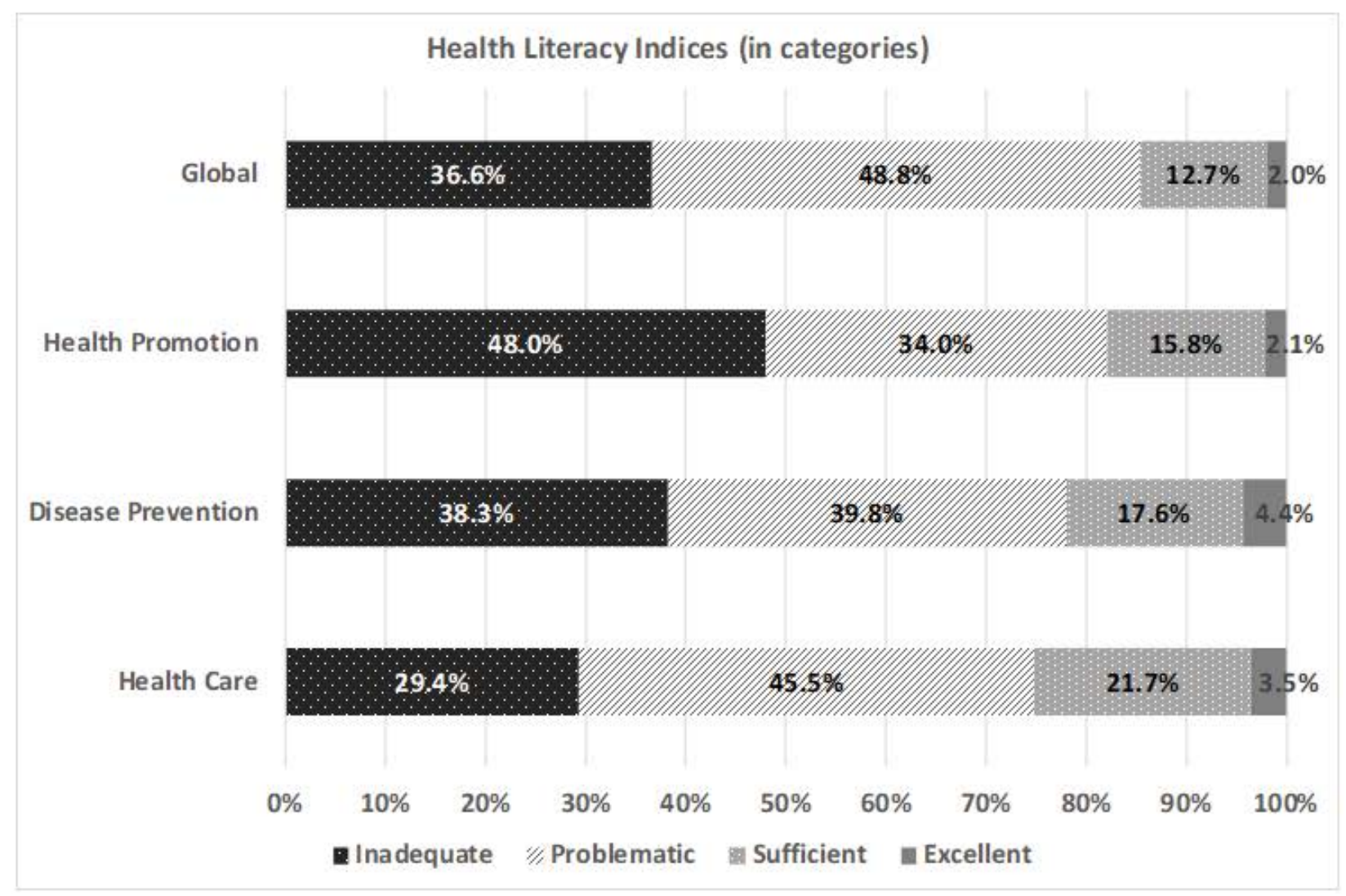

Graph 1: HL of a group of diabetic/hypertensive patients from a region in Northern Portugal $(\mathrm{N}=664)$.

Table 1: HL vs. sex of a group of diabetic/hypertensive patients from a region in Northern Portugal $(N=664)$.

\begin{tabular}{|c|c|c|c|c|c|c|c|c|}
\hline & \multicolumn{2}{|c|}{ Global } & \multicolumn{2}{|c|}{ Health Care } & \multicolumn{2}{|c|}{ Disease Prevention } & \multicolumn{2}{|c|}{ Health Promotion } \\
\hline & Mean & SD & Mean & SD & Mean & SD & Mean & SD \\
\hline Males & 27.33 & 7.86 & 29.00 & 7.91 & 27.18 & 8.48 & 25.49 & 9.43 \\
\hline Females & 25.86 & 7.76 & 27.65 & 7.88 & 26.42 & 8.77 & 23.41 & 9.23 \\
\hline p-value (Mann-Whitney) & \multicolumn{2}{|l|}{0.001} & \multicolumn{2}{|l|}{0.005} & \multicolumn{2}{|l|}{0.044} & \multicolumn{2}{|l|}{0.001} \\
\hline
\end{tabular}

\section{Sample characterization}

This study had the participation of 664 users, $47.7 \%$ male and $52.3 \%$ female, which translates into a very fair sample in terms of gender. As for the age, people aged 60 or older predominated, that is, the majority were adult users approaching the elderly age (61.6\%). These users had low schooling $(54.8 \%$ with only 4 years of compulsory education), were predominantly married $(74.1 \%)$, mostly retired $(56.8 \%)$, with only $30.9 \%$ of them professionally active.

\section{Level of health literacy}

From the general analysis of the scale used (HLS-EUPT) it should be noted that the majority of users presented inadequate or problematic HL level (Graph 1).

From the positioning of the answers it is verified that the users have $\mathrm{HL}$ levels in the middle of the scale of 0 to 50 points (mean of 26.56 and SD of 7.84): This means that $85.4 \%$ of respondents have a $\mathrm{HL}$ considered inadequate ( 0 to 25 points) or problematic ( 26 to 33 points). Of the three areas that make up the scale, health care was the most "positive" (it is easy for them to take care of health) and health promotion was the most "negative" (they have more difficulty in promoting health).

\section{Health literacy vs. Sociodemographic and clinical variables}

Data analysis (Table 1 ) shows that men have more $\mathrm{HL}$ than women, not only at the global level (averages of 27.33 vs. 25.86 , respectively), but also in each of the 3 domains of the scale.

It is also noted that the older the users are, the less $\mathrm{HL}$ they have (Table 2), but this correlation is weak ( $r=$ -0.448).

By analyzing the data, it was also possible to verify (Table 3) that the higher the level of education the higher the level of $\mathrm{HL}$, not only at the global level (increasing averages of 19.20 for people without studies, up to 33.35 for people with secondary education or higher), but as well as in each of the 3 domains of the scale.

Table 4 shows that the professionally active users have more $\mathrm{HL}$ than the inactive, not only at the global 
Table 2: HL vs. age of diabetic/hypertensive patients from a region in Northern Portugal $(\mathrm{N}=664)$.

\begin{tabular}{|l|l|l|l|l|l|}
\hline & Global & Health Care & Disease Prevention & Health Promotion \\
\hline Age & Pearson correlation & $-0.448^{* *}$ & $-0.440^{* *}$ & $-0.379^{* *}$ & $-0.405^{* *}$ \\
& p-value & $<0.001$ & $<0.001$ & $<0.001$ & $<0.001$ \\
\hline
\end{tabular}

Table 3: HL vs. qualifications of diabetic and/or hypertensive patients from a region in the north of Portugal $(N=664)$.

\begin{tabular}{|l|l|l|l|l|l|l|l|l|}
\hline & \multicolumn{3}{l}{ Global } & \multicolumn{3}{l|l}{ Health Care } & \multicolumn{3}{l|}{ Disease Prevention } & \multicolumn{2}{l|}{ Health Promotion } \\
\hline & Mean & SD & Mean & SD & Mean & SD & Mean & SD \\
\hline No studies & 19.20 & 7.71 & 20.48 & 8.88 & 20.03 & 9.87 & 16.89 & 7.21 \\
\hline Compulsory education & 26.49 & 7.27 & 28.35 & 7.34 & 26.68 & 8.08 & 24.22 & 9.01 \\
\hline More than compulsory education & 33.35 & 6.77 & 34.39 & 6.10 & 33.35 & 7.43 & 32.31 & 8.17 \\
\hline p-value (ANOVA) & $<0.001$ & $<0.001$ & $<0.001$ & & $<0.001$ \\
\hline
\end{tabular}

Table 4: $\mathrm{HL}$ vs. professional situation of diabetic/hypertensive patients from a region in the north of Portugal $(\mathrm{N}=664)$.

\begin{tabular}{|c|c|c|c|c|c|c|c|c|}
\hline & \multicolumn{2}{|c|}{ Global } & \multicolumn{2}{|c|}{ Health Care } & \multicolumn{2}{|c|}{ Disease Prevention } & \multicolumn{2}{|c|}{ Health Promotion } \\
\hline & Mean & SD & Mean & SD & Mean & SD & Mean & SD \\
\hline Active & 30.25 & 6.67 & 32.15 & 6.70 & 30.08 & 7.63 & 28.41 & 8.22 \\
\hline Inactive & 24.91 & 7.77 & 26.57 & 7.81 & 25.31 & 8.66 & 22.62 & 9.32 \\
\hline p-value (Mann-Whitney) & \multicolumn{2}{|c|}{$<0.001$} & \multicolumn{2}{|c|}{$<0.001$} & \multicolumn{2}{|c|}{$<0.001$} & \multicolumn{2}{|c|}{$<0.001$} \\
\hline
\end{tabular}

level (averages of 30.25 vs. 24.91, respectively), but also in each of the 3 domains of the scale.

\section{Clinical variables}

Regarding the clinical variables, it was possible to verify that $50 \%$ of the users were diabetic, about 4 out of 5 respondents were hypertensive and about one third reported having the 2 pathologies at the same time. In addition to diabetes and/or hypertension, onethird of participants reported having other diseases. The majority of users use Family Health Units (86.3\%), to the detriment of differentiated health care $(30.1 \%)$ (This question allowed more than one answer).

The majority of respondents considered that both physicians and nurses contribute to their $\mathrm{HL}$, with a higher prevalence for physicians $78.9 \%$ and $66.4 \%$ referred nurses (this question allowed for more than one response).

When asked to suggest measures that could increase their HL, only 1 in 5 respondents answered, of which almost half reported the dissemination of more health information and a quarter suggested that health professionals should devote more time to informing users.

\section{Discussion}

In this study, which had the collaboration of a group of users enrolled in three ACES, the sample was characterized by its homogeneity with regard to sex, adult users approaching the elderly, mostly retired and with low levels of schooling. They were diabetic or hypertensive and some even carry other pathologies. Most have turned to primary health care (FHU) for monitoring and follow-up of their disease.
Based on the objectives of this investigation, it was verified that a group of diabetic and/or hypertensive patients under treatment in three Family Health Units of a region in the North of Portugal presented an inadequate or problematic level of $\mathrm{HL}$. These results are corroborated by several national and international studies $[15,22,26-31]$.

The agreement of the results of this study with the remaining empirical evidence reinforces the need for health professionals to be aware of the importance of $\mathrm{HL}$ because, as Osborn [32], mentions, people with low $\mathrm{HL}$ tend to have more complications resulting from poor chronic diseases of which they are carriers, namely hypertension and DM. With such limited levels of $\mathrm{HL}$, it is crucial that health professionals, health agencies, government and society in general invest in health education for the population in the various domains, enabling them to effectively manage their health [22].

Particularly for the three domains that make up the $\mathrm{HL}$ scale, the health care dimension was the one with the highest results, with health promotion having the lowest levels. These results are also in agreement with the other studies, namely the study carried out by Espanha, Ávila and Mendes [28].

It is highlighted in this study that the sociodemographic variables influence the users' HL levels. Male participants were at a higher HL level, which is in line with the study by Saboga-Nunes, Sorensen, Rodrigues [30]. However, other studies point out that there is no relationship between the sex variable and the $\mathrm{HL}$ level $[28,33]$.

It was verified that, the more education the users 
have, the higher the $\mathrm{HL}$ level is. According to Pedro, Amaral, Escoval [15] there is a relationship between the level of schooling and the $\mathrm{HL}$ level, which is corroborated by authors such as Gonçalves [34], Espanha, Ávila, \& Mendes [28]. Low schooling according to Margoto, Colombo, Gallani [35] is considered a risk factor that could trigger a greater number of hospitalizations, due to an increase in the incidence of chronic disease exacerbations. Thus, the higher the level of schooling, the better the ability to understand and adhere to the therapeutic regime [26].

In the relationship between the age variable and the $\mathrm{HL}$ level, it was found that adults have more $\mathrm{HL}$ than the elderly. This evidence has already been reported in several studies, notably by Davey [33], as one of the main influencers of the HL level of populations worldwide. Pedro, Amaral, Escoval [15] report that as the age increases, the level of health literacy tends to decrease. This seems to be a factor of agreement and risk in $\mathrm{HL}$, since several authors point out the elderly as the most vulnerable group $[22,28,30]$.

It should be noted that the professionally active users had higher HL levels when compared to the retired ones. In 2016, a group of researchers reached similar results to those found in the present study [28], indicating that people who were employed presented better levels of HL compared to the rest $[15,22,30]$.

This trend of outcome may be related to the fact that active people interact with colleagues and other social agents, which may contribute to the increase in the level of HL.

It was explicit that users perceive the doctor and the nurse as fundamental educators to increase their level of $\mathrm{HL}$. They were of the opinion that these professionals should provide more information to guide them in their health project and they would like these professionals to make more time available in the consultations.

\section{Limitations}

There are limitations to our study that warrant further discussion. Firstly, the fact that data were collected from a sample living in a specific region with a small representation of the population. However, it should be noted that these data can provide a significant contribution to the (re)definition of the HL promotion strategies on in the region where the study was conducted. Considering the specific characteristics of this study, the results answered the research question, identifying a predominance of an inadequate or problematic HL level.

\section{Conclusion}

The results presented here refer to an operational strategy to identify the HL level of a group of users from a specific region of northern Portugal. It responds to a topic from the European Union's strategic health plan and the National Health, Literacy and Self-Care program. The evidence found represents a further set of indicators for the multidisciplinary team of health professionals, especially in the Family Health Units, to have these values as a reference in planning the activities and outlining strategies to improve their users' $\mathrm{HL}$ levels. We suggest a multidisciplinary investment in the three dimensions of $\mathrm{HL}$, in order to effectively manage resources and increase health gains.

\section{Funding}

This research did not receive any specific Grant from funding agencies in the public, commercial or not-forprofit sectors.

\section{Conflict of Interest}

None to declare.

\section{Acknowledgments}

The authors would like to thank all the participants, the entire team of professionals and the three clusters of healthcare centers where the data was collected, for the opportunity.

\section{References}

1. Salazar L, Crosby R, DiClemente R (2015) Research methods in health promotion. John Wiley \& Sons, San Francisco SA.

2. National Institute of Statistic [NIS] (2014) Doença Crónica em Portugal.

3. Directorate General of Health (2016) A Saúde dos Portugueses.

4. Organization for Economic Co-operation and Development [OECD] (2017) Health at a Glance 2017.

5. World Health Organization [WHO] (2015) Hypertension.

6. Serra C (2016) Três milhões de portugueses são hipertensos. Correio da Manhã.

7. Pereira D, Costa N, Sousa A, Jardim P, Zanini C (2012) Efeito de intervenção educativa sobre o conhecimento da doença em pacientes com diabetes mellitus. Rev Latino-Am Enfermagem 20: 478-485.

8. European Commission (2007) Together for Health: A Strategic Approach for the EU 2008-2013.

9. Soares D, Viamonte S, Magalhães S, Ribeiro MM, Barreira A, et al. (2013) Que fatores determinam os níveis de atividade física após programa de reabilitação cardíaca? Acta Med Port 26: 689-698.

10. Kristine Sorensen, Stephan Van den Broucke, James Fullam, Gerardine Doyle, Jürgen Pelikan, et al. (2012) Health literacy and public health: A systematic review and integration of definitions and models. BMC Public Health 12: 80.

11. Kristine Sorensen, Jürgen M Pelikan, Florian Röthlin, Kristin Ganahl, Zofia Slonska, et al. (2015) Health literacy in Europe: Comparative results of the European health literacy survey (HLS-EU). Eur J Public Health 25: 1053-1058.

12. Directorate General for Health (2017) Programa nacional de educação para a saúde, literacia e autocuidados.

13. Health Regulatory Entity (2017) Literacia em direitos dos utentes de cuidados de saúde.

14. Intellicare (2016) Literacia em Saúde. 
15. Pedro A, Amaral O, Escoval A (2016) Literacia em saúde, dos dados à ação: Tradução, validação e aplicação do European Health Literacy Survey em Portugal. Revista Portuguesa de Saúde Pública 34: 259-275.

16. Peterson PN, Shetterly SM, Clarke CL, Bekelman DB, Chan PS, et al. (2011) Health literacy and outcomes among patients with heart failure. JAMA 305: 1695-1701.

17. European Commission (2005) Luxembourg declaration on patient safety.

18. European Commission (2012) Annual Work Plan for the Health Programme for 2013.

19. Roediger A (2013) Making health literacy a priority in EU policy. European Public Health Alliance, Bruxelas.

20. Aronis KN, Edgar B, Lin W, Martins MAP, Paasche-Orlow MK, et al. (2017) Health literacy and atrial fibrillation: Relevance and future directions for patient-centred care. Eur Cardiol 12: 52-57.

21. Minal S Kale, Alex D Federman, Katherine Krauskopf, Michael Wolf, Rachel O'Conor, et al. (2015) The association of health literacy with illness and medication beliefs among patients with chronic obstructive pulmonary disease. PLoS One 10: e0123937.

22. Martins C (2018) Literacia em saúde numa Comunidade da Região Centro.

23. Despacho n. ${ }^{\circ}$ 3618-A/2016 (2016) Gabinete do Secretário de Estado Adjunto e da Saúde. Diário da República, 2. ${ }^{a}$ série - N. 49 - 10, Ministério da Saúde, Lisboa.

24. HLS-EU Consortium (2012) Comparative report of health literacy in Eight EU Member State (Second Extended and Revised Version). The European Health Literacy Survey HLS-EU.

25. Think Tank Capacitação do Cidadão em Saúde (2015) Questionário europeu de literacia em saúde aplicado em Portugal: Apresentação dos resultados preliminares.
26. Araújo I (2018) Literacia em Saúde de utentes com hipertensão e diabetes de uma região do norte de Portugal. Revista de Enfermagem Referência IV: 73-82.

27. Costa A, Saboga-Nunes L, Costa L (2016) Avaliação do nível de literacia para a saúde numa amostra portuguesa. Boletim Epidemiológico: Instituto Nacional de Saúde $\mathrm{Dr}^{\circ}$ Ricardo Jorge 17: 38-40.

28. Espanha, R, Ávila P, Mendes R (2016) Literacia em Saúde em Portugal. Lisboa: Fundação Calouste Gulbenkian.

29. Miranda N, Loureiro I (2010) Promover a Saúde: dos fundamentos à acção. Almedina, Coimbra.

30. Saboga-Nunes L, Sorensen K, Rodrigues E (2015) Burden das doenças crónicas não transmissíveis e o papel da literacia para a saúde na sua prevenção/controle: Resultados do estudo european health literacy survey no contex to português (HLS-EU-PT). Revista Direção-Geral da Saúde 3: $31-32$.

31. Saúde que Conta-ENSP/Lilly Portugal (2016) Questionário Europeu de Literacia em Saúde em Portugal.

32. Osborn CY, Cavanaugh K, Wallston KA, Kripalani S, Elasy TA, et al. (2011) Health literacy explains racial disparities in diabetes medication adherence. J Health Commun 16: 268-278.

33. Davey J, Holden CA, Smith BJ (2015) The correlates of chronic disease-related health literacy and its components among men: A systematic review. BMC Public Health 15: 589.

34. Gonçalves A (2015) Literacia em Saúde e utilização dos serviços de saúde.

35. Margoto G, Colombo R, Gallani M (2009) Características clinicas e psicossociaisde pacientes com insuficiência cardíaca que interna por descompensação clinica. Revista Escola de Enfermagem da USP, 43. 